\title{
Pentacene Based Organic Field Effect Transistor Using Different Gate Dielectric
}

\author{
Ayat J. Kadhima $^{\text {a*, Estabraq T. Abdullahb } \oplus^{b} \text {, Abdulhadi K. Judranc }}{ }^{c}$ \\ ${ }^{a}$ Laser and Optoelectronic Engineering Dept., University of Technology-Iraq, Alsina’a Street, 10066 Baghdad, Iraq. \\ ${ }^{b, c}$ College of Science Department of Physics, University of Baghdad, Baghdad, Iraq. \\ *Corresponding author Email: jkadhim950@gmail.com
}

\section{H I G H L I G H T S}

- Modeling of Organic field effect transistors were conceded.

- Focusing on the effect of dielectric materials on the OFET performance.

- Comparison between two different dielectric materials (PVP, $\mathrm{ZrO} 2$ ) was considering.

- I-V characteristics were analyzed and studied.

\section{A R T I C L E I N F O}

\section{Handling editor: Jawad K. Oleiwi}

Keywords:

Dielectric materials

Organic field effect transistors

PVP

$\mathrm{ZrO}_{2}$

\begin{abstract}
A B S T R A C T
This paper presents the electrical behavior of the top contact/ bottom gate of an organic field-effect transistor (OFET) utilizing Pentacene as a semiconductor layer with two distinctive gate dielectric materials Polyvinylpyrrolidone (PVP) and Zirconium oxide $\left(\mathrm{ZrO}_{2}\right)$ were chosen. The influence of the monolayer and bilayer gates insulator on OFET performance was investigated. MATLAB software was used to simulate and determine the electrical characteristics of a device. The output and transfer characteristics were studied for $\mathrm{ZrO}_{2}, \mathrm{PVP}$ and $\mathrm{ZrO}_{2} / \mathrm{PVP}$ as an organic gate insulator layer. Both characteristics show a high drain current at the gate dielectric $\mathrm{ZrO}_{2} / \mathrm{PVP}$ equal to $-0.0031 \mathrm{~A}$ and $-0.0015 \mathrm{~A}$ for output and transfer characteristics respectively, this can be attributed to an increase in the dielectric capacitance. Trans conductance characteristics also studied the gate dielectric materials and show the $\mathrm{ZrO}_{2} / \mathrm{PVP}$ gate dielectric having a higher value from the monolayer, indicating the effect of dielectric capacitance.
\end{abstract}

\section{Introduction}

Small molecular organic semiconductors have a great interest because of their good facilities, lightweight, and easy fabrication under the ambient condition at low cost [1]. The importance of organic semiconductors appears in devices such as transistors[2], solar cells [3], sensors [4], light-emitting diode [5]. Although, these materials typically exhibit low charge carrier mobility, poor environmental stability and a short operational lifetime comparing with inorganic counterparts [6]. Among these small semiconductors, Pentacene is a promising material for a modern application, it is an organic semiconductor molecule $\left(\mathrm{C}_{22} \mathrm{H}_{14}\right)$ with high mobility and carrier and the most promising p-type materials to use in the fabrication of organic field-effect transistor (OFET) devices, typically its charge carrier mobility's ranging between $0.1-0.7 \mathrm{~cm}^{2} / \mathrm{V} . \mathrm{s}$. [7]. The gate dielectric materials and the interface between the gate dielectric materials and the active region are very effective in OFET performance. The organic-inorganic dielectric materials will play a significant role because of their features including low leakage current, decreases in threshold voltage and power dispersion with good thermal stability [8] [9]. Polymer dielectrics show several advantages against inorganic dielectric materials including transparent transistors and flexible display. One of the most interesting polymers is poly vinyl pyro linen (PVP), it is transparent, cross-linkable flexibility which has a great dielectric properties and a high transporter versatility of $3-5 \mathrm{~cm}^{2} \mathrm{~V}^{1} \mathrm{~s}^{1}[10]$. Numerous inorganic metal oxides of high-k concentrated to date incorporate $\mathrm{HfO}_{2}$ [11], $\mathrm{TiO}_{2}$ [12], Zirconium oxide $\left(\mathrm{ZrO}_{2}\right)$ [13]. This work aims to enhance the performance of Pentacene-based OFET depending on two different gate dielectric materials $\left(\mathrm{ZrO}_{2}\right.$ and PVP) by using it as monolayer and bilayer. 


\section{Device Structure}

Pentacene-based OFET with bottom-gate/top contact with 50nm thickness; the parameters used in this work are listed in Table 1. The schematic structure of the Pentacene-based OFETs has appeared in Figure 1.

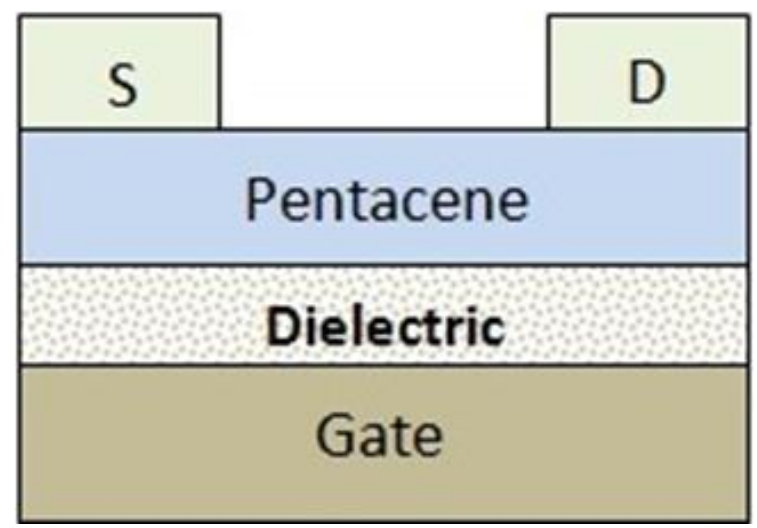

Figure 1: Schematic of OFET

Table 1: Physical parameter for simulation structure

\begin{tabular}{ll}
\hline Parameter & Value \\
\hline Channel length, L & $1 \mu \mathrm{m}$ \\
Thickness, t & $100 \mathrm{~nm}$ \\
Channel width, W & $2.1 \mu \mathrm{m}$ \\
Dielectric constant for PVP, k & 4.5 \\
Dielectric constant for ZrO2, k & 23 \\
Mobility, $\mu$ & $5 \mathrm{Cm} 2 / \mathrm{V} . \mathrm{S}$ \\
Threshold voltage, Vth & 360 \\
\hline
\end{tabular}

\section{Simulation}

A typical model of field-impact transistors gives Id in the direct regime [14].

$$
\mathrm{I}_{\mathrm{d}}=\frac{\mathrm{WC}_{\mathrm{i}}}{\mathrm{L}} \mu \times\left[\left(\mathrm{V}_{\mathrm{g}}-\mathrm{V}_{\mathrm{T}}\right) \times \mathrm{V}_{\mathrm{d}}-\frac{\mathrm{V}_{\mathrm{d}}^{2}}{2}\right]
$$

With $\mathrm{V}_{\mathrm{d}}<\mathrm{V}_{\mathrm{g}}-\mathrm{V}_{\mathrm{T}}$

$$
\mathrm{I}_{\mathrm{d}}=\frac{\mathrm{WC}_{\mathrm{i}}}{2 \mathrm{~L}} \mu_{\mathrm{sat} .} \times\left(\mathrm{V}_{\mathrm{g}}-\mathrm{V}_{\mathrm{T}}\right)^{2}
$$

While the trans conductance of indirect and the immersion locale of the OFET is given by [15]

$$
\begin{array}{lc}
\text { The Linear region } & \mathrm{g}_{\mathrm{m}}=\frac{\partial \mathrm{I}_{\mathrm{d}}}{\partial \mathrm{V}_{\mathrm{g}}}=\mu \mathrm{C}_{\mathrm{i}} \frac{\mathrm{W}}{\mathrm{L}} \mathrm{V}_{\mathrm{d}} \\
\text { The saturation region } & \mathrm{g}_{\mathrm{m}}=\frac{\partial \mathrm{I}_{\mathrm{D}}}{\partial \mathrm{V}_{\mathrm{g}}}=\mu \mathrm{C}_{\mathrm{i}} \frac{\mathrm{W}}{\mathrm{L}}\left(\mathrm{V}_{\mathrm{g}}-\mathrm{V}_{\mathrm{T}}\right)
\end{array}
$$

Where $\mathrm{W}$ and $\mathrm{L}$ are the channel width and length, individually. $\mathrm{C}_{\mathrm{i}}$ the geometric capacitance of the dielectric layer, $\mathrm{V}_{\mathrm{g}}$ is the voltage applied to the entryway contact, $\mathrm{V}_{\mathrm{d}}$ is the voltage applied to the channel contact, and $\mu$ is the mobility. MATLAB recreation was utilized to extricate parameters, for example, portability from the electrical portrayal of Pentacene-based OFETs.

\section{Results and Discussion}

\subsection{Output Characteristics}

Figures 2 and 3 show OFET-based Pentacene for PVP and $\mathrm{ZrO}_{2}$ as natural protector layers individually. It shows a regular yield bend of a field-impact transistor (FET) which demonstrates that solitary gaps are gathered at the semiconductor-dielectric interface and flow stream from the source to the channel through the channel area when negative entryway voltages are applied. In this way, the OFET is working in the p-direct activity in aggregation mode with expanding negative channel current. 


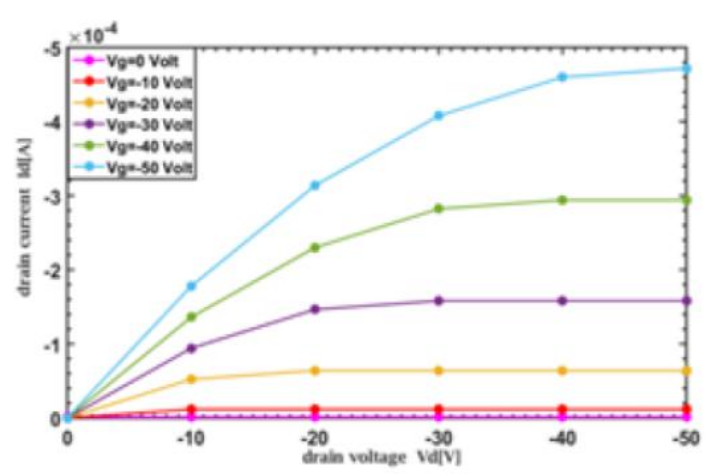

Figure 2: Output Characteristics of gate insulator PVP

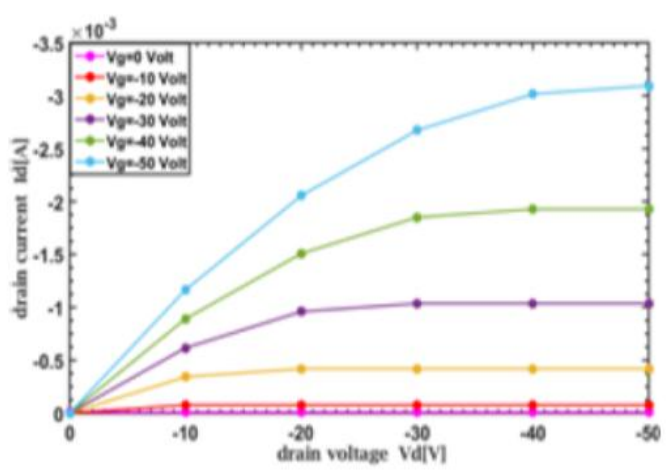

Figure 3: Output Characteristics of gate insulator $\mathrm{ZrO} 2$

The drain current increases with increasing the negative drain voltage till arises saturation region and this is because of the channel pinch-off. It can be the observed improvement of the drain current by using $\mathrm{ZrO}_{2}$ insulator against PVP insulator such behavior can be attributed to the differences in dielectric constant for the two materials which leads to an increase in the effective capacitance $\mathrm{Ci}$, which is defined as $\mathrm{Ci}$, which is defined as [16]:

$$
\mathrm{C}_{\mathrm{i}}=\boldsymbol{k} \circ \varepsilon / \mathrm{t}
$$

Which the carriers charge density increasing too

$$
\mathrm{Q}=\mathrm{Ci}(\mathrm{Vg}-\mathrm{VT})
$$

Figure 4, shows more increase in the $\mathrm{I}_{\mathrm{d}}$ for $\mathrm{ZrO}_{2} / \mathrm{PVP}$ comparing with $\mathrm{PVP}$ and $\mathrm{ZrO}_{2}$, because of the increase of the total dielectric capacitance $\mathrm{C}_{\text {total }}$, which is given by Eq. (7):

$$
\mathrm{C}_{\text {total }}=\mathrm{CPVP}+\mathrm{CZrO}_{2}
$$

The highest current that can be obtained for $\mathrm{ZrO}_{2} / \mathrm{PVP}$ of OFETs is $\mathrm{I}_{\mathrm{d}}=-0.0031 \mathrm{~A}$ at $\mathrm{V}_{\mathrm{g}}=-40 \mathrm{~V}$. These high values of the drain current can be associated with the high capacitance of the $\mathrm{ZrO}_{2} / \mathrm{PVP}$ layer.

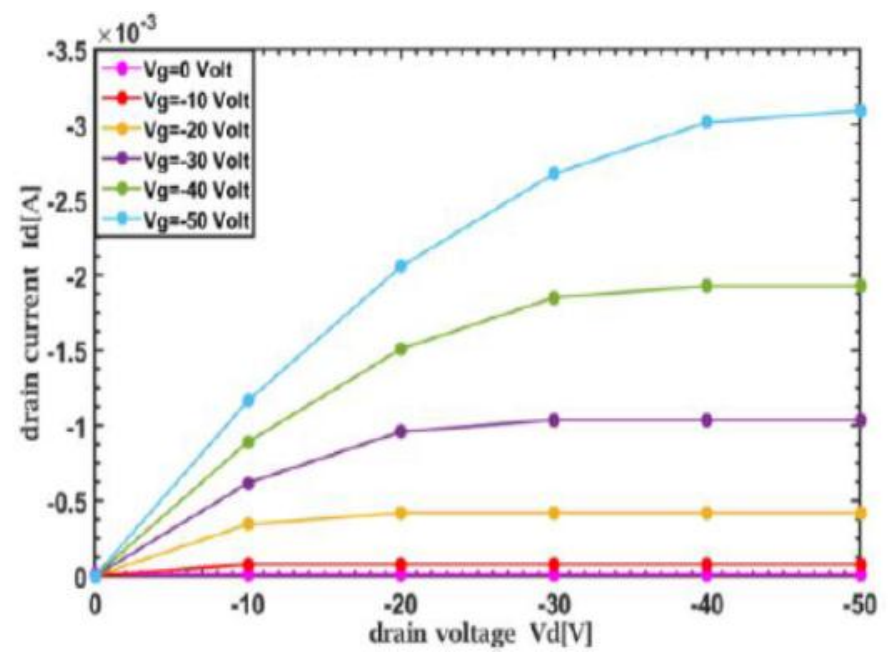

Figure 1: Output Characteristics of gate insulator $\mathrm{PVP} / \mathrm{ZrO}_{2}$

\subsection{Transfer Characteristics}

Figure 5 shows the ordinary exchange qualities of OFET dependent on PVP, $\mathrm{ZrO}_{2}$ and $\mathrm{ZrO}_{2} / \mathrm{PVP}$ dielectric with $\mathrm{V}_{\mathrm{g}}$ clearing from $0 \mathrm{~V}$ to $-50 \mathrm{~V}$ and $\mathrm{V}_{\mathrm{d}}=-50 \mathrm{~V}$ and thickness $=100 \mathrm{~nm}$. Obviously, as the channel inclination expanded the channel field brings down the source to channel hindrance which builds the charge bearer Q, towards the start of the channel; they will cross the boundary, which in the end will prompt an increment of the channel current. The best estimations of the channel flow are gotten for dielectric material $\left(\mathrm{ZrO}_{2} / \mathrm{PVP}\right)$ contrasting and $\mathrm{PVP}$ and $\mathrm{ZrO}_{2}$. The most noteworthy estimation of the channel flow for the $\mathrm{ZrO}_{2} / \mathrm{PVP}$ dielectric of OFETs was acquired right now $0.0015 \mathrm{~A}$ at $\mathrm{V}_{\mathrm{g}}=-40 \mathrm{~V}$. A diminishing in the channel current for all gate voltages contrasting and the most elevated estimation of the channel current at $\mathrm{V}_{\mathrm{g}}=-50 \mathrm{~V}$, is identified with the edge voltage move as it were. 


\subsection{Trans conductance Characteristics}

Figure 6 represents Trans conductance as a function of gate voltage for Pentacene OFET. At $\mathrm{Vg}=0 \mathrm{~V}$ for gate insulator $\mathrm{ZrO}_{2}, \mathrm{PVP}$ and $\mathrm{ZrO}_{2} / \mathrm{PVP}$ high Trans conductance is estimated to equal gm. $=-0.5517 \times 10-4 \mathrm{~A} / \mathrm{V},-0.9931 \times 10-5 \mathrm{~A} / \mathrm{V}$, and $0.6511 \times 10-4 \mathrm{~A} / \mathrm{V}$ respectively. It can be observed an improvement of the Trans conductance by using $\mathrm{ZrO}_{2}$ insulator against PVP insulator, while the best values of the Trans conductance were obtained for dielectric material $\left(\mathrm{ZrO}_{2} / \mathrm{PVP}\right)$ comparing with PVP and $\mathrm{ZrO}_{2}$. These results show an improvement of the trans conductance by using $\mathrm{ZrO}_{2}$ insulator against PVP insulator, while the best values of the trans conductance are obtained for dielectric material $\left(\mathrm{ZrO}_{2} / \mathrm{PVP}\right)$ comparing with PVP and $\mathrm{ZrO}_{2}$, and that is because the increase in the capacitance will induce more charge carriers by the same gate voltage, this behavior is in agreement with Demur et al. [17].

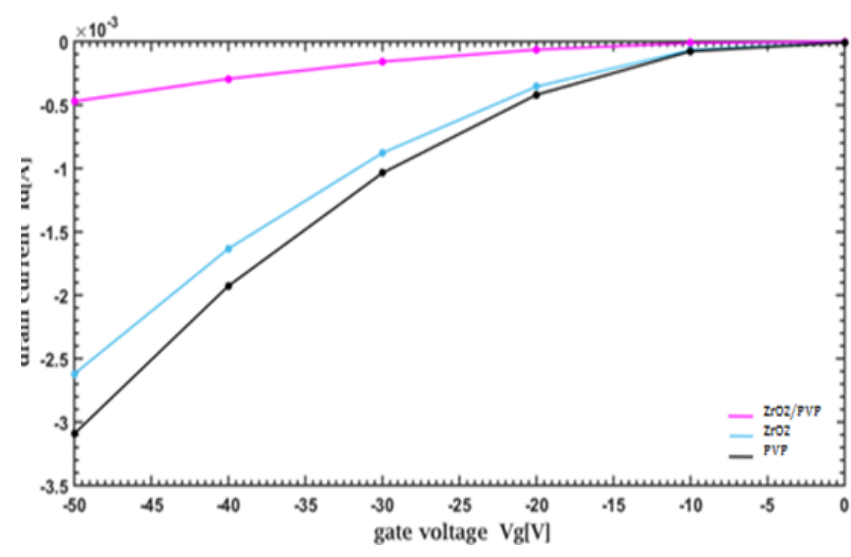

Figure 2: Transfer characteristics of gate insulator $\mathrm{ZrO}_{2} / \mathrm{PVP}$

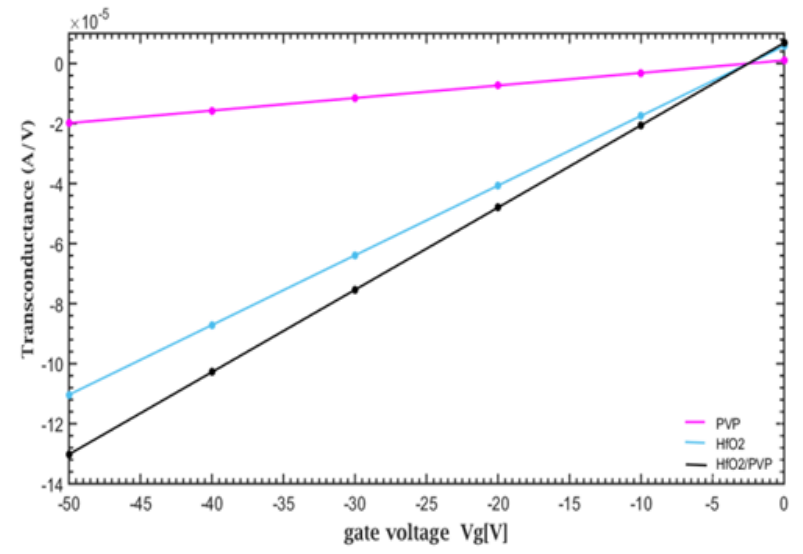

Figure 3: Trans conductance of gate insulators $\mathrm{PVP}, \mathrm{ZrO}_{2}$ and $\mathrm{ZrO}_{2} / \mathrm{PVP}$

\section{CONCLUSIONS}

Top contact/ bottom gate Pentacene-based OFETs having a monolayer and bilayer of PVP and $\mathrm{ZrO}_{2}$ as gate dielectric was studied. The electrical characteristics were calculated by using the MATLAB program in order to study the effect of gate dielectric on the device performance. The results show the best performance was bilayer $\mathrm{ZrO}_{2} / \mathrm{PVP}$ than the monolayer PVP and $\mathrm{ZrO}_{2}$ for $\mathrm{I}-\mathrm{V}$ characteristics and trans conductance.

\section{Author contribution}

All authors contributed equally to this work.

\section{Funding}

This research received no specific grant from any funding agency in the public, commercial, or not-for-profit sectors.

\section{Data availability statement}

The data that support the findings of this study are available on request from the corresponding author.

\section{Conflicts of interest}

The authors declare that there is no conflict of interest.

\section{References}

[1] J. L. Brédas, J. P. Calbert, D. A. Da Silva Filho, and J. Cornil, Organic semiconductors: A theoretical characterization of the basic parameters governing charge transport, Proc. Natl. Acad. Sci. U. S. A., 99, (2002), 5804-5809, doi: 10.1073/pnas.092143399.

[2] Y. Yamashita, Organic semiconductors for organic field-effect transistors, in science and technology of advanced materials, 10, (2009), 1-9, doi: 10.1088/1468-6996/10/2/024313.

[3] J. K. A. Kokil and K. Yang, Techniques for characterization of charge carrier mobility in organic semiconductors, J. Polym. Sci. PART B Polym. Phys., 50, (2012), 1130-1144, doi: 10.1002/polb.23103.

[4] M. A. Najeeb, Z. Ahmad, and R. A. Shakoor, Organic thin-film capacitive and resistive humidity sensors: A Focus Review, Adv. Mater. Interfaces, 1800969, (2018), 1-19, doi: 10.1002/admi.201800969. 
[5] B. K. Periyasamy, S. K. Nayak, S. A. Kumar \& J. S. Shankar, Device engineering aspects of organic light- emitting diodes (OLEDs), Polym. Technol. Mater., 58, (2019), 1597-1624, doi: 10.1080/25740881.2018.1563133.

[6] N. Karl, Charge carrier transport in organic semiconductors, Synth. Met., 134, (2003), 649-657.

[7] M. T. Hussein, E. K. Hassan, and E. T. And Abdullah, Study the high performance of organic semiconductor CuPc field effect transistor, (2015). [Online]. Available: http://inpressco.com/category/ijcet.

[8] S. P.Haridas, S. Sreeshan, S. P. Jacob, S. Khan, and and C. R. Azariah, Fabrication and characterization of flexible metalinsulator- semiconductor field effect transistor (MISFET) using organic ODS and inorganic $\mathrm{ZrO}_{2}$ as dielectric stack materials, Int. J. Trend Res. Dev., 4, (2017), 345-347.

[9] L. Z. Y. Ran, T. F. H.YuFeng, C.ShaoBo, and H. Y. A. L. XiaoJun, Effects of gate dielectric thickness and semiconductor thickness on device performance of organic field-effect transistors based on pentacene, Sci. CHINA Technol. Sci., 57, (2014), 1142-1146.

[10] A. Assis, S. H. T. A, and P. Predeep, Organic field effect transistors - study of performance parameters for different dielectric layer thickness, in AIP Conference Proceedings, 1849, (2017), 020034.

[11] S. Hall, O. Buiu, I. Mitrovic, Y. Lu, and W. Davey, Review and perspective of high-k dielectrics on silicon, J. Telecommun. Inf. Technol., ( 2007), 33-43.

[12] K. C. Y. Lu, W. H. Lee, H. S. Lee, and Y. Jang, Low-voltage organic transistors with titanium oxide-polystyrene bilayer dielectrics, Appl. Phys. Lett., 94, (2009), 1-3, doi: 10.1063/1.3097010.

[13] B. H. Mohammed and E. T. Abdullah, Comparison between horizontal and vertical OFETs by using poly (3Hexylthiophene) (P3HT) as an active semiconductor layer, Iraqi J. Sci., 61, (2020), 1040-1050, doi: 10.24996/ijs.2020.61.5.13.

[14] B. G. Horowitz, Organic Field-Effect Transistors, Adv. Mater., 10, (1998), 365-377.

[15] B. Thokchom, F. Meghdadi, S. Gues, N. Marjanovic, G. Horowitz, P. Lang, S. Bauer and N. S. Sariciftci, Highperformance ambipolar pentacene organic field-effect transistors on poly (vinyl alcohol) organic gate dielectric, Advanced Materials, (2005), 2315-2320, doi: 10.1002/adma.200501109.

[16] B. H. Mohammed and E. T. Abdullah, Study the performance of pentacene based organic field effect transistor by using monolayer, bilayer and trilayer with different gate insulators, Iraqi J. Phys., 18, (2020), 85-97, doi: 10.20723/ijp.18.44.8597.

[17] M. A. Demir, A. Atahan, S. Batci and and M. S. I. Aslan, Organic/inorganic interfaced field-effect transistor properties with a novel organic semiconducting material, Philos. Mag., 96, (2016), 274-285, doi: 10.1080/14786435.2015.1130277. 